The main principle is that an Ngombe word is recognized as belonging to one or other word-group (' part of speech '), not, as in English, by its use and meaning, but by its form. As everybody knows, a Bantu word generally consists of a core or radical, to which are attached various prefixes, infixes, and suffixes. Except in ideophones, this radical in Ngombe has a tone, integral and fixed, high or low. Its basic form is Consonant-Vowel-Consonant, e.g. -OIP- (' shut '). The affixes modify the intrinsic meaning carried by the core and bind the structure of the sentence. There are four major groups of words. The nominals, containing each a fixed prefix, are invariable. The distinction between ' singular' and 'plural' has no grammatical significance: for example, molangi ('bottle') and milangi ('bottles') are two independent words existing each in its own right. There are independent and dependent nominals, the latter containing a variable prefix which imitates the initial syllable of the independent nominals with which they are linked. Older grammarians would call these 'adjectives', ' pronouns', ' adverbs ', 'conjunctions'. The next group, the verbals, differ from nominals in that alternating affixes occur both before and after the central core, the prefixes referring to the preceding independent nominal. The remaining words in Ngombe are either particles, which are used to associate words in sentence-construction, or ideophones. The independent nominals are grouped in genders- ' classes', we used to call them.

Mr. Price proceeds to divide dependent nominals into adnominals and pronominals, corresponding roughly to 'adjectives' and 'pronouns'. Of the former there are two subgroups, those with low-toned and those with high-toned concords. Pronominals also fall into two sub-groups: (a) substitute pronominals (' substantive and possessive pronouns ') and (b) selector pronominals (' demonstratives').

Mr. Price's exposition of the verbals is illuminating. They are best studied, he says, in two groups: one in which the verbal is brought into concordial agreement with a nominal which its is subject; and one in which the verbal is independent of a nominal. He retains the term 'tense' to describe any series of verbals in which the subjective concords (formerly called 'personal pronouns') alone are the alternating factor. Verbals are grouped according to the distinction between time-tenses, zero-time tenses, and timeless tenses-the last introducing ideas of supposition, subjunction, and simultaneity. ('Mood' is eliminated.) Throughout the exposition tones are indicated.

To some old-fashioned grammarians all this may appear to be merely a juggling with terminology, an impish pursuit of new and confusing terms. It is not so. From even a superficial study of Mr. Price's work one gets a clearer understanding of the structure of Bantu than is obtained from the old grammars. Anyone who is contemplating the preparation of a grammar would be well advised to master this new technique.

(Communicated by E. W. Smith)

\title{
A Tigrinya Language Council
}

WhEN, in 1942, the British Ministry of Information in Eritrea founded the first regular weekly paper ever published in Tigrinya, a great many problems presented themselves to the editors. It was not only a question of translating words like Allies, United Nations, bombs, and dictator into Tigrinya, the language of a predominantly agricultural community, but also of creating a style and a spelling suitable for the needs of the average Tigrinya newspaper reader.

Tigrinya is the language of some 450,000 Abyssinians on the Eritrean plateau and of some 800,000 beyond the artificial border in Northern Ethiopia (Tigre province). It is thus, after Arabic and Amharic, the most widely spoken living Semitic language.

Although very little had been printed in Tigrinya until recently, with the exception of the New Testament, a selection from the Psalter, and other Old Testament texts, there has been a fairly extensive correspondence between Eritreans, and an astonishingly acute feeling for 
their language exists among large numbers of Tigrinya speakers. This is partly due to the great influence which Geeez, the classical and ecclesiastical language, still has over its daughter tongues, and partly to the tradition of learning and linguistic as well as theological speculation which has resulted in an unusually high degree of literacy (by African standards) among the inhabitants of the Eritrean plateau and Northern Ethiopia. Moreover, the various missionary societies have in the course of time developed differing systems of spelling and style. To-day there exist two main schools, represented by the Swedish Evangelical Mission on one hand and the Catholic Mission of the Ethiopian rite on the other. While the former has adopted a simplified form of spelling, better suited to educational purposes and to the actual facts of the living language, the latter adheres to the historial and etymological way of writing. There are obvious advantages and disadvantages in both systems, but despite the strong backing which the reform method received in the columns of the Tigrinya Eritrean Weekly News it cannot be said that hitherto the new system has been more successful than Mr. G. B. Shaw's attempts at English spelling reform.

It soon became desirable to have the whim of the sub-editor restrained by a committee of authoritative advisers who, in 1944, were formed into a 'supreme' body of Tigrinya language 'dictators' - the Tigrinya Language Council-an institution probably unique in Africa, though with parallels elsewhere.

The council, as finally constituted, was remarkably representative, including spokesmen of the Coptic and Catholic bishops, Swedish Mission representatives, the Eritrean Inspector of Schools, the pastor of the Seventh Day Adventists, and others. Abba Ya'qob Gebreyesus was elected President. He is a Catholic of the Ethiopian rite, the most notable Eritrean writer, and a grammarian of some repute with a number of grammars and text-books to his credit. He possesses the most complete linguistic library in Eritrea, on which, it is safe to assume, not more than three Europeans have set eyes. Vice-president was Qeshi 'Oqbasgi' Mika' el, Seventh Day Adventist representative, a remarkably learned man who possesses, in addition to his knowledge of four Ethiopian languages, a fair acquaintance with Arabic and Hebrew.

Adaptation of Tigrinya to modern needs proved the less controversial part of the work. The problem was not only how and in what form technical words and other modern conceptions should be allowed hospitality in Tigrinya (in their English or Italian form?), but mainly whether similar words already existed in the vast Ethiopic literature which might be revived and adapted to the purpose in view. Where this was not the case, it was obviously preferable to explore new formations in modern Arabic and Hebrew rather than to embark on new and adventurous ways unconnected with the development in other Semitic languages. Thus, after some uncertainty in the beginning, 'Ministry' was taken over into Tigrinya as 'Ministerya', a form which was considered to follow most closely the general language structure. The word 'information' after unsuccessful trials with ' informěšn' and ' 'informașione' was finally found in the Ge'ez zeña where its original meaning was 'notification', 'story', \&c.

It was a matter of the greatest interest to see African peasants, priests, and so-called grammarians argue for hours and with much fervour about the merits and demerits of spelling reform. The debate was almost invariably on a high level and was conducted with characteristic Ethiopian eloquence.

Such work, of course, never ends, and it was a matter of disappointment to many when the initial enthusiasm ebbed, political considerations entered the picture, and the Committee became moribund. However, the Tigrinya Language Council has its modest place in the history of African cultural endeavours.

(Communicated by E. Ullendorff) 